\title{
Biochemical Properties of Cytochrome P-450 in Relation to Steroid Oxygenation ${ }^{a}$
}

\author{
MINOR J. COON AND KUNIYO INOUYE \\ Department of Biological Chemistry \\ Medical School \\ The University of Michigan \\ Ann Arbor, Michigan 48109-0010
}

The studies from other laboratories presented at this symposium indicate that congenital adrenal hyperplasia is a complex human disorder involving, among other factors, a genetic deficiency in 21-hydroxylase. This hydroxylase is one of many oxygenases that function in lipid transformations and are recognized from their biochemical properties as falling in the class of red, carbon-monoxide-binding pigments known as cytochrome P-450. ${ }^{1}$

As judged by the reversal of $\mathrm{CO}$ inhibition by exposure to monochromatic light at about $450 \mathrm{~nm}$, the 21 -hydroxylation of $17 \alpha$-hydroxyprogesterone was the first such steroid conversion shown to be P-450-catalyzed. ${ }^{2}$ The 21 -hydroxylase is required in the synthesis of adrenal corticosteroids since it catalyzes the oxygenation of $\Delta^{4}-3$ ketosteroids such as progesterone, as well as of $17 \alpha$-hydroxyprogesterone. Like the $17 \alpha$-hydroxylase, the 21 -hydroxylase is located in the endoplasmic reticulum of the adrenal cortex and requires NADPH-cytochrome P-450 reductase to effect electron transfer. The 21-hydroxylase has been purified from bovine adrenal cortical microsomes. ${ }^{3-6}$ The minimal molecular weight of the purified enzyme has been stated to range from 47,000 to 52,000 , and P-450 specific contents as high as $20 \mathrm{nmol}$ of heme per milligram of protein have been reported. The enzyme is apparently immunochemically distinct from the other adrenal P-450's and contains some carbohydrate. It is low-spin as isolated, but can be converted to the high-spin form by the addition of substrate. The purified enzyme is specific for 21 -hydroxylation and, unlike the $17 \alpha$-hydroxylase, shows no change in activity upon the addition of cytochrome $b_{5}{ }^{5}$ The purified preparation catalyzes the demethylation of benzphetamine at about $30 \%$ of the rate of 21 -hydroxylation of $17 \alpha$-hydroxyprogesterone, but is apparently inactive in the demethylation of $p$-nitroanisole or the $p$-hydroxylation of aniline. Of particular interest, the 21-hydroxylase has also been purified to homogeneity from porcine adrenocortical microsomes, and the cysteine-containing peptides from this protein have been sequenced as described below.?

In the present paper, some fundamental biochemical properties of cytochrome P-450 are reviewed and some implications for steroid hydroxylation are discussed. In particular, the known influence of environmental factors on the activities of many P-450's raises the question of whether some of the puzzling variables in congenital adrenal hyperplasia and in the function of the 21-hydroxylase are related to exposure to xenobiotics.

\footnotetext{
${ }^{a}$ This work was supported by grant no. AM-10339 from the National Institutes of Health.
} 


\section{BIOCHEMISTRY OF CYTOCHROME P-450}

The active site of cytochrome P-450, as proposed previously, ${ }^{8}$ is pictured in FIGURE 1. This site contains iron protoporphyrin IX, presumably in a hydrophobic cleft in the protein, which favors the binding of a variety of nonpolar substrates or portions of substrates, including physiologically occurring compounds such as steroids, prostaglandins, and fatty acids. In some instances, a variety of foreign compounds, including drugs, carcinogens, anesthetics, pesticides, organic solvents, etc., are also accommodated by the substrate-binding site. The heme, which is not bound covalently to the protein, is always penta- or hexacoordinate, four of the ligands being provided by the $\mathrm{N}$ atoms of the porphyrin ring. The fifth ligand is believed to be a specific cysteine residue of the polypeptide chain, 9,10 and the sixth coordination position of the iron is occupied by an easily exchangeable oxygen ligand, perhaps from water ${ }^{11,12}$ or the hydroxyl group of a serine or threonine residue, ${ }^{13,14}$ in the native, ferric state of the enzyme. A tyrosine residue is also a likely candidate. 15,16 Upon reduction of the iron, the sixth position

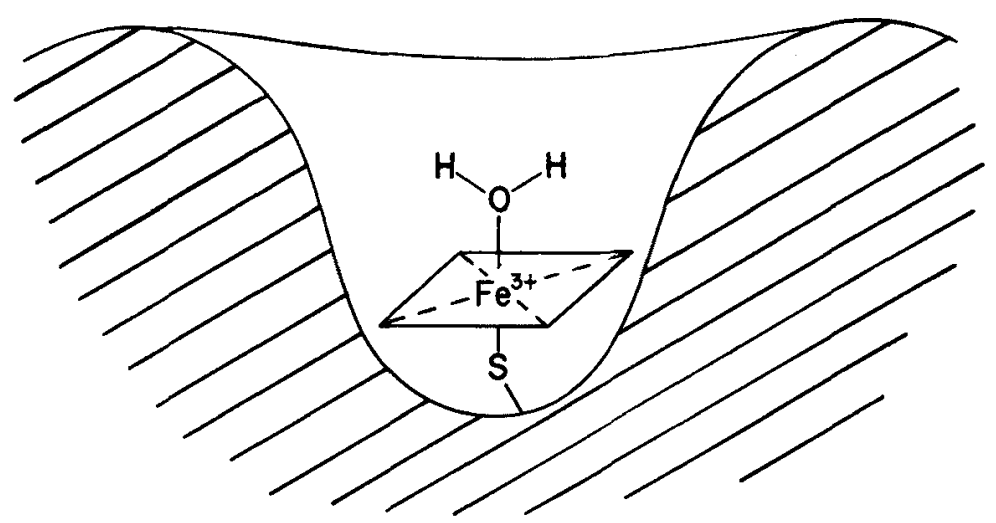

FIGURE 1. Model of the active site of cytochrome P-450.

becomes the site of $\mathrm{O}_{2}$ binding, but other diatomic ligands such as $\mathrm{CO}, \mathrm{NO}$, and $\mathrm{CN}^{-}$ may compete with oxygen. Thus, $\mathrm{CO}$ gives the complex an absorption maximum at about $450 \mathrm{~nm}$ and is inhibitory to the action of the enzyme because of the competitive displacement of $\mathrm{O}_{2}$. Although it would be highly desirable in all instances to name these enzymes by their function, as is often done with the steroid hydroxylases, some forms of the cytochrome have such broad substrate specificity that there is no easy way of choosing among the hundreds of potential substrates and the catalyst is therefore designated by its relative electrophoretic mobility or some other arbitrary system.

The existence of tyrosyl and histidyl residues as well as a cysteinyl residue in the substrate-binding site was suggested by chemical modification studies. ${ }^{17,18}$ In this connection, we have recently observed that upon the binding of the detergent CHAPS [3-(3-cholamidopropyl)-dimethylammonio-1-propanesulfonate] to rabbit P-450 isozyme 2, a unique absorption difference spectrum is seen that is similar to that induced by the binding of type II substrates (amines). This detergent may disaggregate the P-450 into monomers without denaturation of the protein structure and concomitant 
conversion of P-450 to P-420. The formation of the CHAPS-induced difference spectrum is slower than that caused by substrate binding, which is probably diffusioncontrolled. Since CHAPS is not a type II substrate, the difference spectrum observed may be due to the movement of the amine moiety of some amino acid residue such as histidine, tryptophan, lysine, or arginine to the heme, with resulting ligation. The results obtained by chemical modification ${ }^{17,18}$ implicate a histidyl residue. We have observed also that $\mathrm{CO}$ binding to reduced P-450 isozyme 2 is inhibited in the presence of CHAPS and that the extent of this inhibition with varying detergent concentrations corresponds to that which would be predicted by CHAPS-induced spectral changes. These results strongly suggest that a conformational change occurs in the substratebinding site, followed by ligation of the amine moiety (presumably of histidine) to the heme.

NADPH is the primary electron donor to the cytochrome, with NADPHcytochrome P-450 reductase serving as the carrier in microsomes, which is shown in FIGURE 2. The microsomal system, in contrast to that in mitochondria, does not utilize an intermediate iron-sulfur protein and, thus, makes use of direct flavin-heme electron transfer. The flavoprotein in this case is unusual in containing both FMN and FAD; ${ }^{19}$ studies with FMN-depleted enzyme have shown that FMN directly reduces the P-450 heme. ${ }^{20}$ The proposed scheme in FIGURE 3 accounts for the evidence presently available from this and other laboratories for electron transfer and oxygen activation in this enzyme system. The steps, beginning with the resting ferric enzyme at the top of the cycle and going clockwise, are as follows: (1) substrate binding; (2) transfer of the first electron from the reductase; (3) dioxygen binding to the ferrous protein, thus giving the ferrous-dioxygen complex, which can also be written as a resonance form, ferricsuperoxide; (4) transfer of the second electron, which may come via the reductase or, in some instances, from ferrous cytochrome $b_{5} ;(5)$ splitting of the oxygen-oxygen bond to yield $\mathrm{H}_{2} \mathrm{O}$ and a postulated iron-oxene species; (6) hydrogen abstraction from the substrate to give a transient substrate carbon radical and an iron-bound hydroxyl radical or equivalent, as proposed by Groves et al. ${ }^{21}$ on the basis of the intramolecular isotope effect observed with deuteronorbornane; and (7) radical recombination followed by ( 8 ) dissociation from the enzyme of the resulting product, $\mathrm{ROH}$. Thus, the resting ferric state of the enzyme is regenerated prior to another cycle. The reactions proposed are compatible with the known stoichiometry of the hydroxylation reaction: ${ }^{22}$

$$
\mathrm{RH}+\mathrm{O}_{2}+\mathrm{NADPH}+\mathrm{H}^{+} \rightarrow \mathrm{ROH}+\mathrm{H}_{2} \mathrm{O}+\mathrm{NADP}^{+}
$$

An interesting variation is now recognized in which a peroxy compound $(\mathrm{XOOH})$,

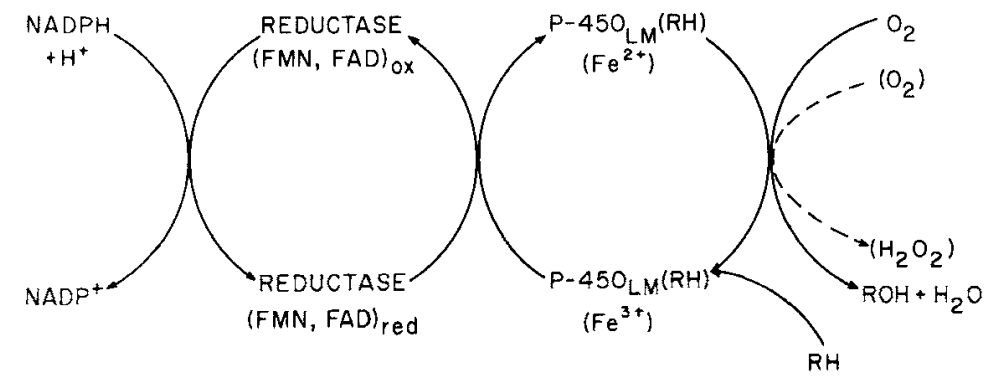

FIGURE 2. Electron transfer reactions in the microsomal P-450 system. 


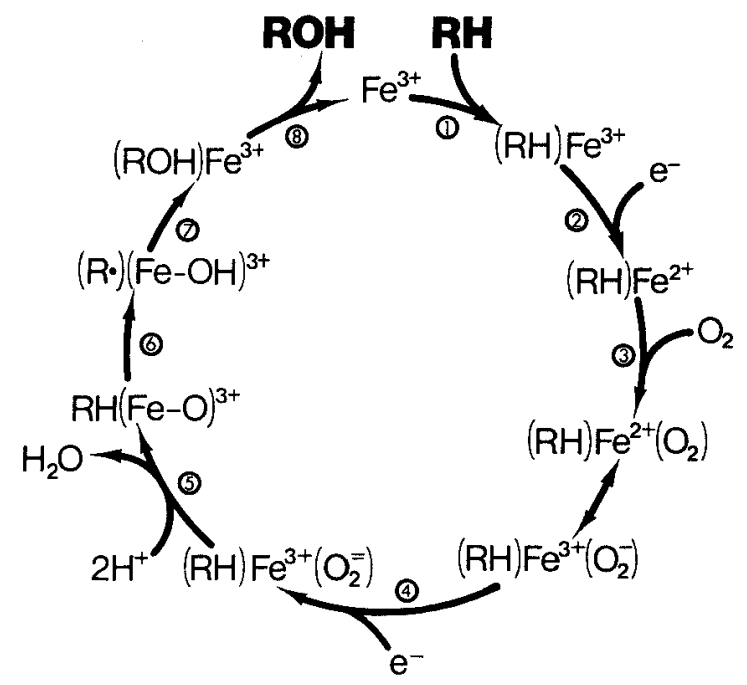

FIGURE 3. Proposed scheme for mechanism of action of cytochrome P-450 in hydroxylation reactions, taken from reference 8 . $\mathrm{RH}$ represents a substrate and $\mathrm{ROH}$ represents the corresponding product.

which may be hydrogen peroxide or an organic peracid or hydroperoxide, provides the oxygen atom in a reaction not requiring molecular oxygen, NADPH, or the reductase: ${ }^{23}$

$$
\mathrm{RH}+\mathrm{XOOH} \rightarrow \mathrm{ROH}+\mathrm{XOH}
$$

Clearly, variations on this scheme are required to account for the mechanism of other reactions involving $\mathrm{P}-450$, in processes as diverse as dehalogenation and desulfuration.

\section{MULTIPLICITY OF P-450 ISOZYMES}

As reviewed elsewhere, ${ }^{1,24,25}$ the total number of mammalian P-450 isozymes is large, but not yet known exactly, and they appear to fall into two large groups: those concerned primarily with lipid metabolism, and those having very broad substrate specificity and acting both on lipids and foreign compounds. The latter type, which is found in hepatic microsomes, includes those P-450 cytochromes that were the first to be purified to homogeneity and characterized biochemically. For example, the presently known isozymes from rabbit liver microsomes are shown in TABLE 1. Since the discovery and determination of the properties of a number of these has already been reviewed, ${ }^{1,24,25}$ only more recent developments will be emphasized here. Isozyme 1 has been obtained from uninduced animals, ${ }^{26}$ isozyme $3 \mathrm{a}$ from alcohol- and imidazoleinduced animals ${ }^{27,28}$ (and, apparently, also after benzene treatment ${ }^{29}$ ), and isozyme 5 from lung ${ }^{30}$ (corresponding to a form in liver ${ }^{31}$ ); in addition, the polymorphism of isozyme $3 \mathrm{~b}$ has been demonstrated. ${ }^{32}$ Furthermore, Wikvall and associates ${ }^{33}$ have purified liver microsomal isozymes with the same electrophoretic behavior as isozyme 
$4,^{34}$ but apparently otherwise distinct, and they have also recently isolated a liver mitochondrial P-450 with cholesterol 26 -hydroxylase activity. ${ }^{35}$ Some of the forms isolated by Sato and colleagues ${ }^{36}$ are believed to be different from those studied in other laboratories; two of these are listed here as $\mathrm{P}-450_{7}$ and $\mathrm{P}-450_{8}$, but it should be noted that in this case the nomenclature with substrates is not based on electrophoretic mobility. Many of these isozymes are active in the hydroxylation of testosterone and androstenedione in various positions ${ }^{25}$ or of other steroids.

P-450 isozyme 1 has been reported to have the highest activity of six rabbit liver cytochromes examined for the 21-hydroxylation of progesterone. ${ }^{26,37}$ The purified enzyme has a minimal molecular weight of about 48,000 and exhibits a $K_{\mathrm{m}}$ and $V_{\max }$ for progesterone hydroxylation of $1.6 \mu \mathrm{M}$ and $7.1 \mathrm{~min}^{-1}$, respectively, which are values very similar to those reported for the adrenal 21 -hydroxylase. ${ }^{5}$ However, unlike the adrenal enzyme, which hydroxylates only at the 21-position, isozyme 1 also hydroxylates at the $6 \beta$ and $16 \alpha$ positions of progesterone. ${ }^{5}$ In addition, this purified hepatic enzyme catalyzes the 2 -hydroxylation of estradiol. ${ }^{38}$ Whether the liver enzyme has

TABLE 1. Rabbit Liver Microsomal Cytochrome P-450 Isozymes and Inducers

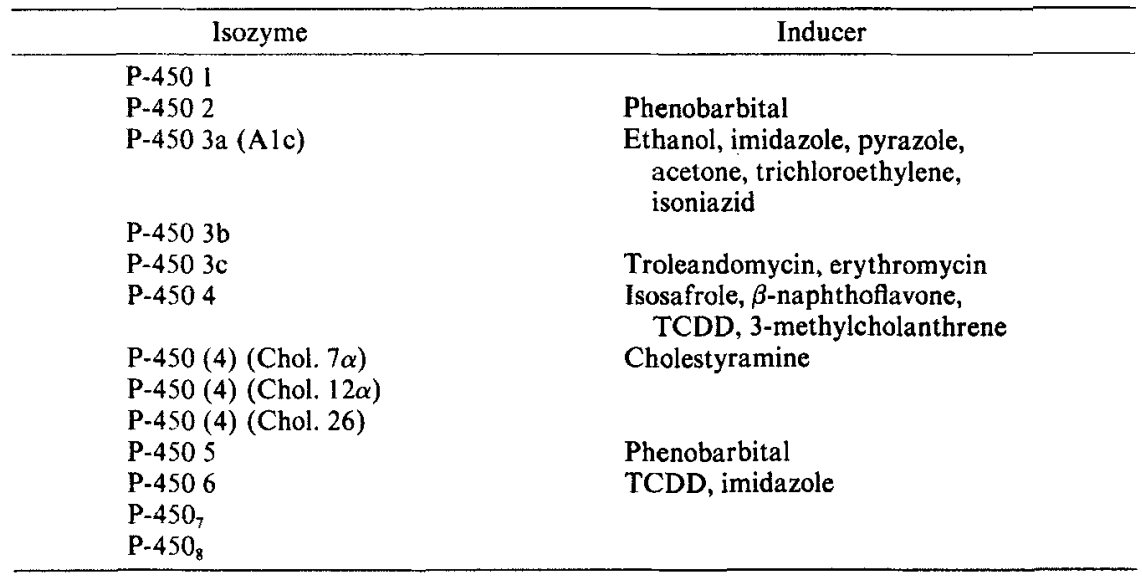

extensive structural features in common with those of the adrenal microsomal enzyme and, furthermore, whether it provides a physiological pathway for the extra-adrenal production of hormones remains to be determined.

Since a cysteine residue is known to provide the sulfur ligand to the heme iron atom in the P-450 cytochromes, as indicated above, it may be presumed that the cysteine peptide providing this function would be conserved during evolution. A comparison of three conserved cysteine peptides in various P-450 cytochromes is given in FIGURE 4, in which the areas of structural homology with respect to isozyme 4 are enclosed in boxes. The P-450's represented are rabbit isozymes $4^{39}$ and $2,{ }^{40,41}$ rat isozymes $b,{ }^{42,43} c{ }^{44-46}$ and $d,{ }^{47,48}$ mouse isozymes 1 and $3,{ }^{49,50}$ bacterial $P-450_{\text {cam }},{ }^{51}$ and pig adrenal microsomal 21-hydroxylase. ${ }^{7,44}$ The most extensive homology is seen with the cysteine near the $\mathrm{COOH}$-terminus, which may possibly be the source of the sulfur ligand. Recent experiments in this laboratory (unpublished results, S. D. Black and M. J. Coon), in which rabbit isozyme 2 was treated with DTNB or monobromobimane appear to rule 

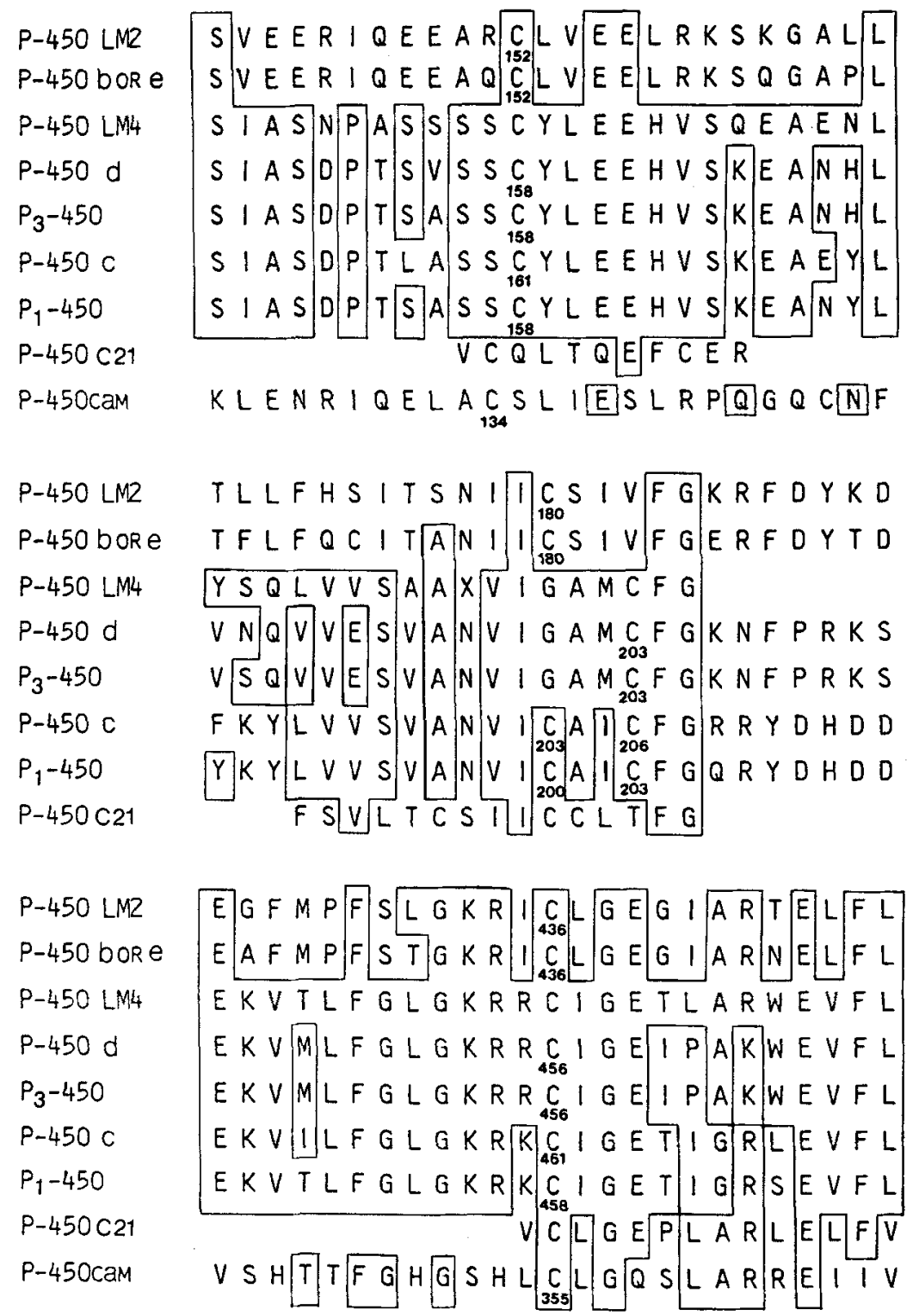

FIGURE 4. Comparison of the sequence of cysteine peptides in various P-450 cytochromes. Homology with respect to rabbit liver microsomal P-450 isozyme 4 is shown by the enclosed areas. 
out Cys-152 as providing the sulfur ligand, but it may have some other function such as the binding of NADPH-cytochrome P-450 reductase.

\section{DISCUSSION}

Despite some differences in substrate specificity, the P-450 cytochromes are believed to be similar both in their ability to bind hydrophobic substrates and molecular oxygen at the active site and in the manner in which they bring about the reductive activation of molecular oxygen, with one atom going to water and the other being inserted into the substrate. The activity of this family of enzymes in substrate monooxygenation varies in some instances with the age and sex of the animal, as well as with exposure to foreign chemicals. Indeed, with those P-450's having broad substrate specificity, a myriad of physiologically occurring lipids and foreign compounds serves both as substrates and as mutually competitive inhibitors. The more specific, extrahepatic steroid-hydroxylating cytochromes are known in some instances to oxygenate certain xenobiotics as well, but the possibility has not been studied adequately as to whether those xenobiotics that are not oxygenated at a significant rate are nevertheless bound at the active site and, thus, serve as nonmetabolizable, competitive inhibitors. Thus, an enormous variety of foreign organic compounds in our environment (estimated to be at least 100,000 in technologically advanced countries) could play an indirect role in adrenal hyperplasia. Exposure to foreign compounds, including ethanol, food additives, insecticides, dyes, combustion products, solvents, and so forth, may occur both pre- and postnatally. The P-450 system is also sensitive to dietary alterations, not only because of the need for vitamins and other building blocks in the biosynthesis of NADPH, flavins, heme, and proteins, but also because the integrity of biological membranes in which these enzymes are embedded is subject to nutritional influences. ${ }^{52-57}$ Thus, genetic control of the 21-hydroxylase and other steroid hormonemetabolizing P-450's could be modified by environmental factors.

\section{SUMMARY}

The P-450 cytochromes have been characterized biochemically in recent years as a family of monooxygenases that reductively activate molecular oxygen for insertion into steroids and other physiologically occurring lipids. Many of these enzymes are also known to bind and oxygenate a host of foreign compounds, including alcohol, drugs, pesticides, anesthetics, and mutagens. Some of the poorly understood variations in congenital adrenal hyperplasia may represent nutritional effects on the P-450 oxygenase systems or the ability of xenobiotics to interfere with normal steroid metabolism by these versatile cytochromes.

\section{REFERENCES}

1. CoON, M. J. \& D. R. Koop. 1983. P-450 oxygenases in lipid transformation. In The Enzymes, vol. XVI. P. D. Boyer, Ed.: 645-677. Academic Press. New York.

2. Estabrook, R. W., D. Y. COOPER \& O. Rosenthal, 1963. Biochem. Z. 338: 741-755.

3. Kominami, S., S. MORI \& S. TAKeMORI. 1978. FEBS Lett. 89: 215-218.

4. Kominami, S., H. OCHI, Y. Kobayashi \& S. Takemori. 1980. J. Biol. Chem. 255: 3386 3394.

5. Hiwatashi, A. \& Y. Ichikawa. 1981. Biochim. Biophys. Acta 664: 33-48. 
6. Bumpus, J. A. \& K. M. Dus. 1982. J. Biol. Chem. 257: 12696-12704.

7. Yuan, P-M., S. Nakajin, M. Haniu, M. Shinoda, P. F. Hall \& J. E. Shively. 1983. Biochemistry 22: 143-149.

8. White, R. E. \& M. J. Coon. 1980. Annu. Rev. Biochem. 49: 315-356.

9. Champion, P. M., B. R. Stallard, G. C. Wagner \& I. C. Gunsalus. 1982. J. Am. Chem. Soc. 104: 5469-5472.

10. Hahn, J. E., K. O. Hodgson, L. A. Anderson \& J. H. Dawson. 1982. J. Biol. Chem. 257: 10934-10941.

11. Griffin, B. W. \& J. A. Peterson. 1975. J. Biol. Chem. 250: 6445-6451.

12. Philson, S. B., P. G. Debrunner, P. G. Schmidt \& I. C. Gunsalus. 1979. J. Biol. Chem. 254: 10173-10179.

13. Ullrich, V., H. Sakurai \& H. H. Ruf. 1979. Acta Biol. Med. Ger. 39: $287-297$.

14. RUF, H. H., P. WeNDE \& V. UllRich. 1979. J. Inorg. Biochem. 11: 189-204.

15. Ruckpaul, K., H. Rejn, D. P. Ballou \& M. J. CoON. 1980. Biochim. Biophys. Acta 626: 41-56.

16. Jänig, G-R., A. Makower, H. Rabe, R. Bernhardt \& K. Ruckpaul. 1984. Biochim. Biophys. Acta 787: 8-18.

17. Dus, K. M. 1980. Application of covalent affinity and photoaffinity probes targeted for the active site of P-450 hemeproteins. In Biochemistry, Biophysics, and Regulation of Cytochrome P-450. J-Å. Gustafsson, J. Carlstedt-Duke, A. Mode \& J. Rafter, Eds.: 129132. Elsevier. Amsterdam.

18. Gibson, G. G. \& P. P. TAmbrini. 1980. Spin equilibrium of purified cytochrome P-450. Effect of substrate and histidine modification. In Biochemistry, Biophysics, and Regulation of Cytochrome P-450. J-Å. Gustafsson, J. Carlstedt-Duke, A. Mode \& J. Rafter, Eds.: 133-136. Elsevier. Amsterdam.

19. Vermilion, J. L. \& M. J. CoON. 1978. J. Biol. Chem. 253: 2694-2704.

20. Vermilion, J. L. \& M. J. COON. 1978. J. Biol. Chem. 253: 8812-8819.

21. Groves, J. T., G. A. McClusky, R. E. WhITE \& M. J. Coon. 1978. Biochem. Biophys. Res. Commun. 81: 154-160.

22. NoRdBlom, G. D. \& M. J. COON. 1977. Arch. Biochem. Biophys. 180: 343-347.

23. Nordblom, G. D., R. E. White \& M. J. Coon. 1976. Arch. Biochem. Biophys. 175: 524-533.

24. Lu, A. Y. H. \& S. B. WeST. 1980. Pharmacol. Rev. 31: 277-295

25. COON, M. J., S. D. BLACK, D. R. KoOP, E. T. MORGAN \& G. E. TARR. 1982. Structural and catalytic studies with purified microsomal enzymes. In Microsomes, Drug Oxidations, and Drug Toxicity. R. Sato and R. Kato, Eds.: 13-23. Japan Scientific Societies Press. Tokyo,

26. Dieter, H. H., U. MUller-Eberhard \& E. F. Johnson. 1982. Biochem. Biophys. Res. Commun. 105: 51 5-520.

27. Koop, D. R., E. T. Morgan, G. E. Tarr \& M. J. Coon. 1982. J. Biol. Chem. 257: 8472-8480.

28. KOOP, D. R. \& M. J. Coon. 1984. Mol. Pharmacol. 25: 494-501.

29. InGELMAN-SundBerG, M. \& I. JohANSSON. 1984. J. Biol. Chem. 259: 6447-6458.

30. Slauter, S. R., C. R. Wolf, J. P. Marciniszyn \& R. M. Philpot. 1981. J. Biol. Chem. 256: 2499-2503.

31. Serabitt-Singh, C. J., P. W. Albro, I. G. C. Robertson \& R. M. Philpot. 1983. J. Biol. Chem. 258: $12827-12834$.

32. DieTER, H. H. \& E. F. JoHNSON. 1982. J. Biol. Chem. 257: 9315-9323.

33. Bostrom, H. \& K. Wikvall. 1982. J. Biol. Chem. 257: 11755-11759.

34. Haugen, D. A. \& M. J. CoON. 1976. J. Biol. Chem. 251: 7929-7939.

35. Wikvall, K. 1984. J. Biol. Chem. 259: 3800-3804.

36. Aoyama, T., Y. Imai \& R. Sato. 1982. Multiple forms of cytochrome P-450 from liver microsomes of drug-untreated rabbits: Purification and characterization. In Microsomes, Drug Oxidations, and Drug Toxicity. R. Sato \& R. Kato, Eds.: 83-84. Japan Scientific Societies Press. Tokyo.

37. DieTer, H. H., U. MULler-Eberhard \& E. F. JohnSON. 1982. Science 217: 741-743.

38. Johnson, E. F., H. H. Dieter, G. E. Schwab, I. Reubi \& U. Muller-Eberhard. 1982. 
Rabbit microsomal cytochrome P-450 1: A cytochrome linked to variations in rabbit steroid hormone metabolism. In Cytochrome P-450: Biochemistry, Biophysics, and Environmental Implications. E. Hietanen, M. Laitenen \& O. Hänninen, Eds.: 337-340. Elsevier Biomedical Press. Amsterdam.

39. Fujita, V. S., S. D. Black, G. E. TarR, D. R. Koop \& M. J. Coon. 1984. Proc. Natl. Acad. Sci. USA 81: 4260-4264.

40. TARR, G. E, S. D. Black, V. S. Fujita \& M. J. Coon. 1983. Proc. Natl. Acad. Sci. USA 80: $6552-6556$.

41. HeinemanN, F. S. \& J. Ozols. 1983. J. Biol. Chem. 258: 4195-4201.

42. Fujil-Kuriyama, Y., Y. Mizukami, K. Kawajiri, K. Sogawa \& M. Muramatsu. 1982. Proc. Natl. Acad. Sci. USA 79: 2793-2797.

43. Yuan, P-M., D. E. Ryan, W. Levin \& J. E. Shively. 1983. Proc. Natl. Acad. Sci. USA 80: $1169-1173$.

44. Haniu, M., P-M. Yuan, D. E. Ryan, W. Levin \& J. E. Shively. 1984. Biochemistry 23: $2478-2482$.

45. Yabusaki, Y., M. Shimizu, H. Murakami, K. Nakamura, K. Oeda \& H. OhKawa. 1984. Nucl. Acids Res. 12: 2929-2938.

46. Sogawa, K., O. Gotoh, K. Kawajiri \& Y. Fujil-Kuriyama. 1984. Proc. Natl. Acad. Sci. USA 81: $5066-5070$.

47. Kawajiri, K., O. Gotoh, K. Sogawa, Y. Tagashira, M. Muramatsu \& Y. FujhKuriyama. 1984, Proc. Natl. Acad. Sci. USA 81: 1649-1653.

48. Haniu, M., D. E. Ryan, W. Levin \& J. E. Shively. 1984. Proc. Natl. Acad. Sci. USA 81: $4298-4301$.

49. Kimura, S., F. J. Gonzalez \& D. W. Nebert. 1984. Nucl. Acids Res. 12: 2917-2928.

50. Kimura, S., F. J. Gonzalez \& D. W. Nebert. 1984. J. Biol. Chem. 259: 10705-10713.

51. Haniu, M., L. G. Armes, K. T. Yasunobu, B. A. Shastry \& I. C. Gunsalus. 1982. J. Biol. Chem. 257: 12664-12671.

52. LU, A. Y. H. 1976. Fed. Proc. 35: 2460-2463.

53. Zannoni, V. G. \& P. H. Sato. 1976. Fed. Proc. 35: 2464-2469.

54. Campbell, T. C. \& J. R. Hayes. 1976. Fed. Proc. 35: 2470-2474.

55. Wade, A. E. \& W. P. Norred. 1976. Fed. Proc. 35: 2475-2479.

56. BeCKING, G. C. 1976. Fed. Proc. 35: 2480-2485.

57. Alvares, A. P., E. J. Pantuck, K. E. Anderson, A. Kappas \& A. H. Conney. 1979. Drug Metab. Rev. 9: 185-205. 